DEUTSCHE AKADEMIE DER WISSENSCHAFTEN ZU BERLIN SCHRIFTEN DER SEKTION FÜR VOR- UND FRUHGESCHICHTE

\title{
HOHEN VIECHELN
}

EIN MITTELSTEINZEITLICHER WOHNPLATZ

IN MECKLENBURG

von

EWALD SGHULDT

mit Beiträgen von

O. GEHL, H. SCHMITZ, E. SOERGEL

und H. H. WUNDSCH

Mit 13 Textabbildungen, 19 Tabellen,

144 Tafeln und 3 Beilagen

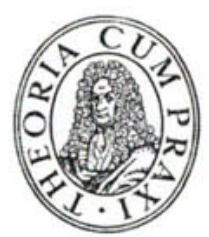

A K A D E M I E - VER LAG - B E R L I N

1961 
Erschienen im Akademie-Verlag GmbH, Berlin W 8, Leipziger Straße 3-4 Copyright 1961 by Akademie-Verlag GmbH

Lizenz-Nr. $202 \cdot 100 / 146 / 61 \cdot$ MdI der DDR, Nr. 6093

Anfertigung der Ätzungen: Sachsendruck Plauen

Gesamtherstellung: Druckhaus „Maxim Gorki“, Altenburg

Bestellnummer 2044/10

Preis DM 64,-

Printed in Germany

ES $14, \mathrm{C}$ 